\title{
Prediction of final settlements of buildings constructed on expansive soils
}

\author{
María-de-la-Luz Pérez-Rea ${ }^{1}$, Tania Ayala-Ibarra ${ }^{3}$, Víctor M. Castaño ${ }^{* 2}$ \\ ${ }^{I}$ División de Estudios de Posgrado. Facultad de Ingeniería. Universidad Autónoma de Querétaro. Cerro de las Campanas S/N. Col. \\ Niños Héroes. Querétaro, Qro. México.76010 \\ ${ }^{2}$ Centro de Física Aplicada y Tecnología Avanzada, Universidad Nacional Autónoma de México, Boulevard Juriquilla 3001, \\ Querétaro, Querétaro, México 76230 \\ ${ }^{3}$ Unidad Académica de Ingeniería, Universidad Autónoma de Guerrero, Av. Lázaro Cárdenas, S/N. Ciudad Universitaria. \\ Chilpancingo, Guerrero, México. 39070 \\ *Corresponding author E-mail: meneses@unam.mx
}

Copyright $\odot 2015$ María-de-la-Luz Pérez-Rea et al. This is an open access article distributed under the Creative Commons Attribution License, which permits unrestricted use, distribution, and reproduction in any medium, provided the original work is properly cited.

\begin{abstract}
Because the action of the swelling pressure, the settlements caused by the transmitted load from the structure on expansive soils, and the settlements calculated by classic theories of soils mechanics are different. This swelling pressure acts in opposite direction to the weight of the building. In this paper, the authors propose the use of a volumetric strain coefficient by settlements exp, in a soil-structure interaction algorithm taking into account the expansive soil behavior in the reduction of the settlement magnitude when a building is placed above soil. It's necessary to know the initial properties of the expansive unsaturated soil and the load building conditions. A laboratory process is described for determining the $a_{\text {exp }}$ coefficient.
\end{abstract}

Keywords: Expansive Soils; Settlement; Soil Strain; Soil-Structure Interaction; Swelling Pressure.

\section{Introduction}

Queretaro City is placed on a predominant clayey soil with a significant presence of montmorillonite, on the order of the $40 \%$ [1]. The region corresponds to a semiarid climate, which implies that the soil is subject to significant changes of humidity, having dehydration in spring and moisturizing in summer (figure 1).

In the United States, expansive clays are responsible for many damages in structures. Krohn and Slosson [2] reckoned in approximately 7,000 million dollars per year these affectations. The American Society of Civil Engineers estimates that $25 \%$ of all households in the United States have some damage caused by expansive soils [3].

Construction on expansive soils can usually be solved by using piles. When sallow foundations are used, the expansion pressure must be determined and foundation designed to provide enhanced to counter the pressure of expansion [4]. Still, these soils can create big problems for shallow and deep foundations [5].

The damage generated in the structures founded on these soils is due to that these are not adapted structurally to the answer mechanism taking into account the soil. Soil-structure interaction is an interdisciplinary field between soil mechanics and structural dynamics. Their origin date back to the late nineteenth century and has progressed due to the emergence of powerful computers and simulation tools, mainly to improve seismic safety [6]. Geotechnical performance of the foundation depends on the actions of the superstructure and the response of the soil in contact. The interdependence between the foundation and soil structure is called soil-structure interaction [7].

Because the problem of the soils with potential of volumetric change is, currently a prominent aspect to take into account in the projects of all kinds of constructions, this work attempts to present a methodology for considering the soil deformations in the settlement generated by a building, in which the loads originated by own weight surpass to the expansion forces. This is a problem of settlement diminished for the pressure of expansion. Utilization of a coefficient 
of deformation that takes into account the expansive behavior of the soil, and that it can be measured with conventional laboratory equipment, facilitates the prediction of the actual settlements of the land.

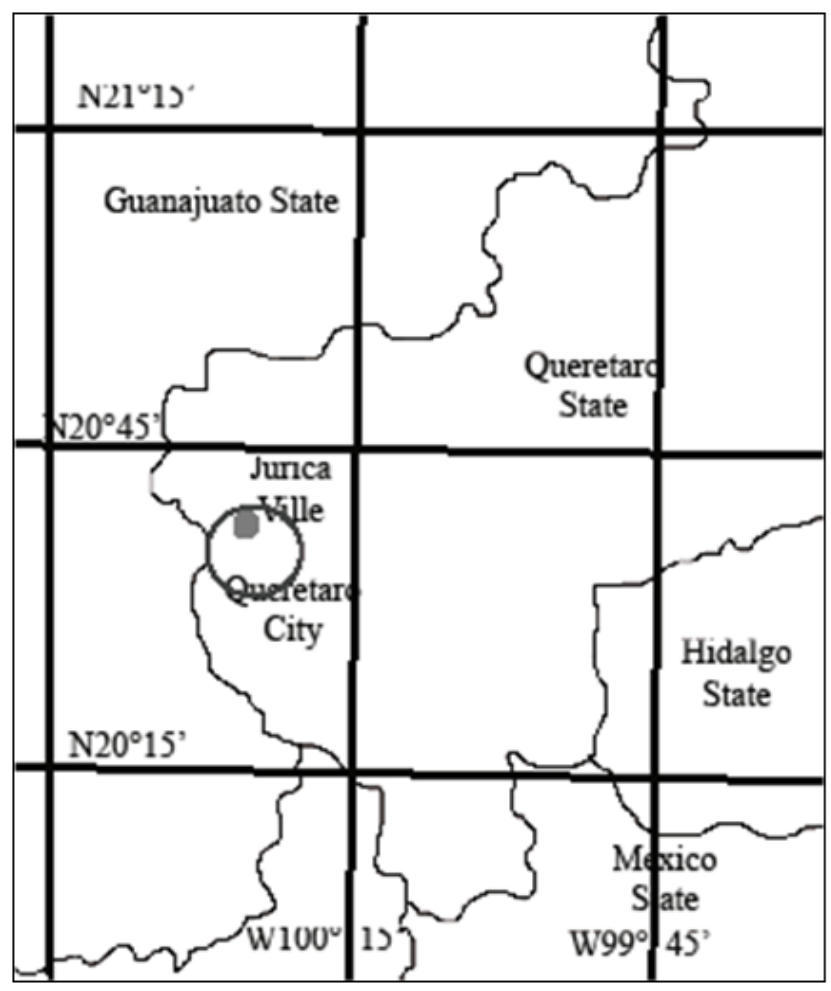

Fig. 1: Geographical Location of the Research Site.

\subsection{Expansive soils}

Expansive clays are those that are susceptible to undergo an appreciable increase of volume when increasing their humidity. The structures constructed on this type of clays are subject to the action of forces that cause up lifting, cracking, and rupture of foundations.

The expansion pressure is the maximum vertical stress that the soil can apply on the foundation in the limit of its expansion. If pressure on the ground is less than the expansion pressure, volume increase occurs, if the pressure of the building is greater than the expansion pressure causes compression volume [8]. The expansion pressure is not a constant and depends on the initial moisture; low initial moisture leads to higher expansive potential; then the expansion pressure for a soil is circumstantial [9].

The irrigation of gardens and the water leaking in pipes also will modify humidity of the original environment. Thus, the active zone (depth in a ground to which it happens periodic humidity changes) will be modified until obtaining another condition of balance where another regularity in the variations of water content is pronounced, which will be able to be repeated annually, whenever the new environmental condition prevails with time.

About the structure, the flocculated particles tend to be more expansive than dispersed clays, although in kneaded compaction, dispersed structures with a greater potential of expansion are created than statically compacted soils with low water contents [10]. The soil suction is an amount of energy that evaluates the capacity of the ground to retain water [11]. Said of another form, the soil suction is a state of negative pressure in the water of an unsaturated soil, which is related to the degree of saturation, the gravity, the size and the form of pores, the superficial tension and the electrical and chemical characteristics of particles of soil and water.

The initial state of stress and the magnitude of the overload also determine the amount of the change of volume. An external applied load acts to balance the repulsive interparticle forces and reduces the expansion [12]. The soil behavior influences in the structure behavior, therefore, the soil behavior is a fundamental part for the design and good operation of the structures.

\section{Methods}

\subsection{Site characterization}


For any project, when the design and construction is carried out is fundamental to realize a basic geotechnical site characterization in which are included the determination of the index and mechanical properties of the soil. For this work undisturbed samples of Jurica, Querétaro, México, were obtained, to a depth of 2,0 m. Subsequently, essays corresponding to properties index were made and the soil classification was obtained through plasticity chart. The measured expansion pressure was equal to seven Ton $/ \mathrm{m} 2$. The results of the soil characterization are summarized in table no. 1 .

Table 1: Summary of the Geotechnical Properties of the Jurica's Soil.

\begin{tabular}{ll}
\hline Gravimetric humidity, $\omega$ & $26 \%$ \\
\hline Specific weight, $\gamma \mathrm{m}$ & $1.7 \mathrm{~T} / \mathrm{m} 3$ \\
Specific gravity, Ss & 2.54 \\
Void ratio, e & 0.87 \\
Porosity, n & 0.47 \\
Saturation degree , G $\omega$ & $76 \%$ \\
Volumetric gravity, $\theta \omega$ & $35 \%$ \\
Liquid limit, LL & $78 \%$ \\
Plastic limit, LP & $33 \%$ \\
Plastic index, IP & $45 \%$ \\
Shrinkage limit, LC & $7 \%$ \\
Linear shrinkage, CL & $21 \%$ \\
Gravel content, G & $3 \%$ \\
Sand content, S & $14 \%$ \\
Fine soils content, F & $83 \%$ \\
\hline
\end{tabular}

\subsection{Analysis procedure}

Classical geotechnical methods are traditionally used for determining the soil characterization focused upon the foundation design. This traditional approach to the soil behavior considers the saturated soil condition; therefore, the expansion pressure is not taken into account. However, an expansive soil will exert an uplifting pressure on the foundation structure reducing the settlements.

The authors are proposing a methodology that considers Zeevaert algorithms of interaction soil-structure (ISS) [13], using a new kind of coefficient associated with the expansive soil behavior [14]. The interaction between the foundation structure and the soil (ISS) consists of finding a system of reactions that applied to the foundation structure and to the soil mass simultaneously, both produce the same configuration of displacements between elements. In this, methodology is necessary to know the volumetric deformation value of the layers, which is determined of analogous way to the described by Zeevaert [13] to obtain the sexp coefficient in its recompression by load theory.

In a previous work, Perez y Cabrera [14] reported that the sexp varies with both the initial soil humidity and the moisture change. It is important when the soil is partially saturated and when the structural pressure on the soil is smaller than the expansive pressure and then the settlements are negatives (upward). Nevertheless, when the structural pressure on the soil is greater than the expansive pressure, the settlements will be positives but lesser than in a nonexpansive soil. In this work, the last case is analyzed considering than the aexp coefficient depends of the initial structural pressure too.

\subsection{Volumetric deformation coefficient due to settlements}

For the determination of the volumetric deformation coefficient due to settlements was necessary to carry out laboratory tests to know vertical, initial and final stresses acting on the foundation soil.

The laboratory test was made in a mechanical oedometer in undisturbed samples of non-saturated expansive soils with natural humidity, taken of the same site from where the samples were taken to realize the characterization described in the previous section. Later, the overburden load was placed, and the specimen was saturated by capillarity until the expansion deformation was developed. This expansion obeys to the expansive soil property only and depends on the initial humidity. It is not considered that it involves stress relaxation by unloading during the expansion stage.

Once the soil was saturated, typical consolidation tests were carried out. Cycles of hysteresis in total load and unloading and similarly for partial stresses lightening are realized with the intention of obtaining the elastic and viscoplastic components of the deformation. The initial deformation by expansion of the soil is considered an important part of the elastic deformation of the material.

\subsection{Calculation of the aexp coefficient}

When a load due to the weight of the building is placed on the foundation (figure 2), the soil is recompressed in its elastic, plastic and visco-plastic components of the deformation [11]: 
$\Delta \varepsilon_{c}=\Delta \varepsilon_{e o}+\Delta \varepsilon_{p o}+\Delta \varepsilon_{v p o}$

For unloading and total recompression $\Delta \sigma_{o i}$ the secant module will be:

$M_{c o}=\frac{\Delta \varepsilon_{e o}}{\Delta \sigma_{c o}}\left(1+\frac{\Delta \varepsilon_{p o}}{\Delta \varepsilon_{e o}}+\frac{\Delta \varepsilon_{v p o}}{\Delta \varepsilon_{e o}}\right)$

Or

$M_{c o}=M_{e o}\left(1+k_{p o}+k_{v p o}\right)$

In the same form for a partial lightening and recompression $\Delta \sigma_{i}$ it is had:

$M_{c i}=M_{e i}\left(1+k_{p i}+k_{v p i}\right)$

And consequently the relation of these modules:

$\frac{M_{c i}}{M_{c o}}=\frac{M_{e i}}{M_{e o}} \cdot \frac{1+k_{p i}+k_{v p i}}{1+k_{p o}+k_{v p o}}$

But

$\frac{M_{e i}}{M_{e o}}=\rho_{e i}$

From

$\frac{M_{c i}}{M_{c o}}=\rho_{e i} \frac{1+k_{p i}+k_{v p i}}{1+k_{p o}+k_{v p o}}$

In an oedometric compressibility test, the terms $\Delta \sigma_{c o}, \Delta \sigma_{i}, \Delta \varepsilon_{p o}, \Delta \varepsilon_{e o}$ and $\Delta \varepsilon_{v p o}$ are obtained from the compressibility curve showed in figure 2. The terms Mco, kpo and kvpo in equation (6) are calculated using the next equations:

$M_{c o}=\frac{\Delta \varepsilon_{e o}}{\Delta \sigma_{c o}} ; \quad k_{p o}=\frac{\Delta \varepsilon_{p o}}{\Delta \varepsilon_{e o}} ; \quad k_{v p o}=\frac{\Delta \varepsilon_{v p o}}{\Delta \varepsilon_{e o}}$

$\Delta \varepsilon_{v p o}$ Is a function of the time interval that the vertical pressure remain on the specimen. 


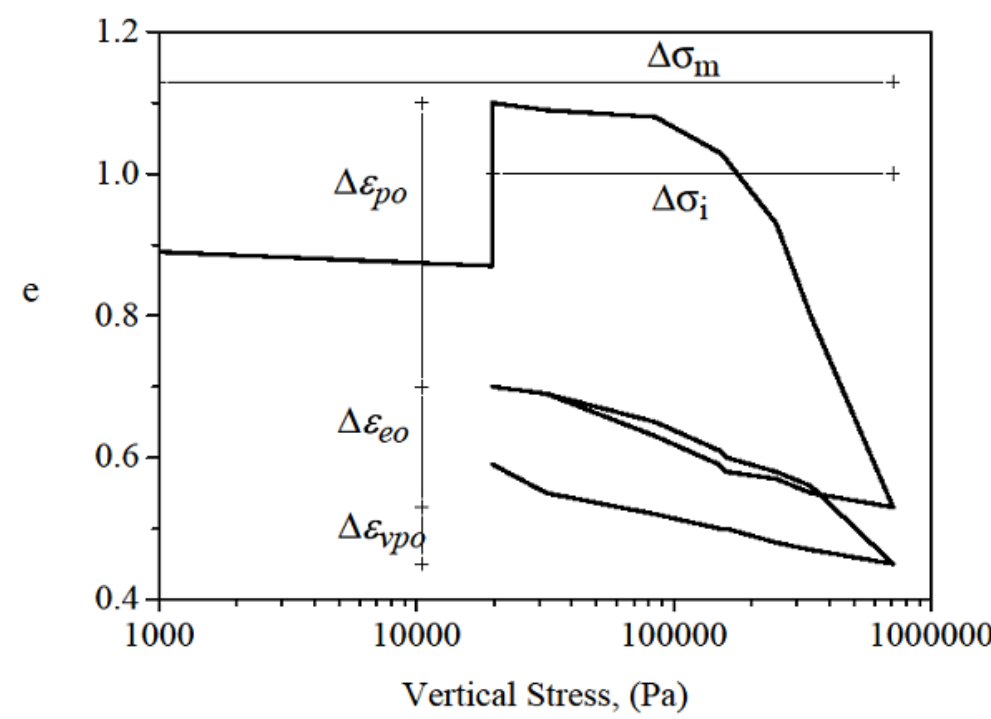

Fig. 2: Compressibility Curve for Jurica's Natural Soil.

The unknown quantities are kpi and kvpi since the Mco, kpo and kvpo values are determined by laboratory tests in specimens of undisturbed soil for the maximum stresses lightening carrying out a hysteretic cycle (figure 2).

$M_{c o}=\frac{\Delta \varepsilon_{c o}}{\Delta \sigma_{c o}}$

An approximated hypothesis can be done that the values kpo and kvpo both are proportional at the level of stress of load applied for partial stress lightening to load applied for total stress lightening

$\frac{k_{p i}}{k_{p o}} \cong \frac{\Delta \sigma_{i}}{\sigma_{c o}}$

$\frac{k_{v p i}}{k_{v p o}} \cong \frac{\Delta \sigma_{i}}{\sigma_{c o}}$

Replacing the equations (9) and (10) in the expression (6) it is obtained

$\frac{M_{c i}}{M_{c o}}=\rho_{e i} \frac{1+\left(k_{p o}+k_{v p o}\right) \Delta \sigma_{i} / \sigma_{c o}}{1+\left(k_{p o}+k_{v p o}\right)}$

Where the recompression factor $\rho_{c}$ is defined by the second term of the equation (10):

$\rho_{c}=\rho_{e i} \frac{1+\left(k_{p o}+k_{v p o}\right) \Delta \sigma_{i} / \sigma_{c o}}{1+\left(k_{p o}+k_{v p o}\right)}$

The strain secant module value for the recompression of the interesting layer will be

$M_{c i}=\rho_{c i} \cdot M_{c o}$

And the volumetric compression coefficient aexp for each one of the layers of thickness di in the soil mass is calculated:

$\alpha_{\text {exp }}=M_{c i} * d_{i}$

\section{Results and discussion}

In order to illustrate the practical way to obtain exp for an expansive soil, an expansion-compressibility-recompression essay was made in an oedometric device in soil from Jurica, which is widely known in the region because of its 
expansive behavior. The investigated layer has a thickness of $2 \mathrm{~m}$. The results are shown in figure 2. Applying the suggested procedure the values for the deformations are obtained:

$$
\begin{aligned}
& \Delta \varepsilon_{e o}=0.172 \\
& \Delta \varepsilon_{p o}=0.4 \\
& \Delta \varepsilon_{v p o}=0.089 \\
& \Delta \sigma_{c o}=689799.8 \mathrm{~Pa} \\
& \Delta \sigma_{i}=673520.7 \mathrm{~Pa}
\end{aligned}
$$

Replacing the values obtained from figure 2 in the equations of (1) to (14), the strain secant module for the layer was initially calculated. After that, aexp was calculated as it follows:

$$
\begin{aligned}
& k_{p o}=\frac{\Delta \varepsilon_{p o}}{\Delta \varepsilon_{e o}}=\frac{0.4}{0.172}=2.326 \\
& k_{v p o}=\frac{\Delta \varepsilon_{v p o}}{\Delta \varepsilon_{e o}}=\frac{0.089}{0.172}=0.517 \\
& M_{e i}=\frac{\Delta \varepsilon_{e o}}{\Delta \sigma_{i}}=\frac{0.172}{673520.7 P a} \\
& M_{e i}=2.5537 E-07 / P a \\
& M_{e o}=\frac{\Delta \varepsilon_{e o}}{\Delta \sigma_{c o}}=\frac{0.172}{689799.8 P a} \\
& M_{e o}=2.4935 E-07 / P a \\
& \rho_{e i}=\frac{M_{e i}}{M_{e o}}=\frac{2.5537 E-07 / P a}{2.4935 E-07 / P a}=1.024 \\
& \rho_{c}=\rho_{e i} \frac{1+\left(k_{p o}+k_{v p o}\right) \Delta \sigma_{i} / \sigma_{c o}}{1+\left(k_{p o}+k_{v p o}\right)}=1.006 \\
& M_{c i}=\rho_{c} \cdot M_{c o}=9.6399 E-07 / P a
\end{aligned}
$$

Therefore aexp is:

$$
\alpha_{\exp }=M_{c i} * d_{i}=9.6399 E-07 m / P a
$$

The aexp value thus obtained will have to be introduced in the equations of ISS of Zeevaert for the calculation of the final settlements.

When the external load on the soil stays constant, the coefficient of volumetric deformation varies with the initial humidity of the soil and with the humidity change [12]. The coefficient decreases when the initial humidity increases. In this work when the humidity stays constant the coefficient decreases when the initial external load increases, which indicates that the heave that will suffer the foundation structure is being affected by the magnitude of the expansion pressure. If the expansion pressure did not act, would have to hope that whichever greater it is the external load, the vertical settlements would have to be proportionally greater.

Is interesting to observe the graphic in figure 3 where the swelling percent decreases with de vertical pressure increment. It can see that after $300 \mathrm{kPa}$, the heave is reduced to zero and the settlements have started. For Jurica's soil then, it could be that a threshold of $300 \mathrm{kPa}$ is the critical value for the vertical pressure between the heave and the settlement. 


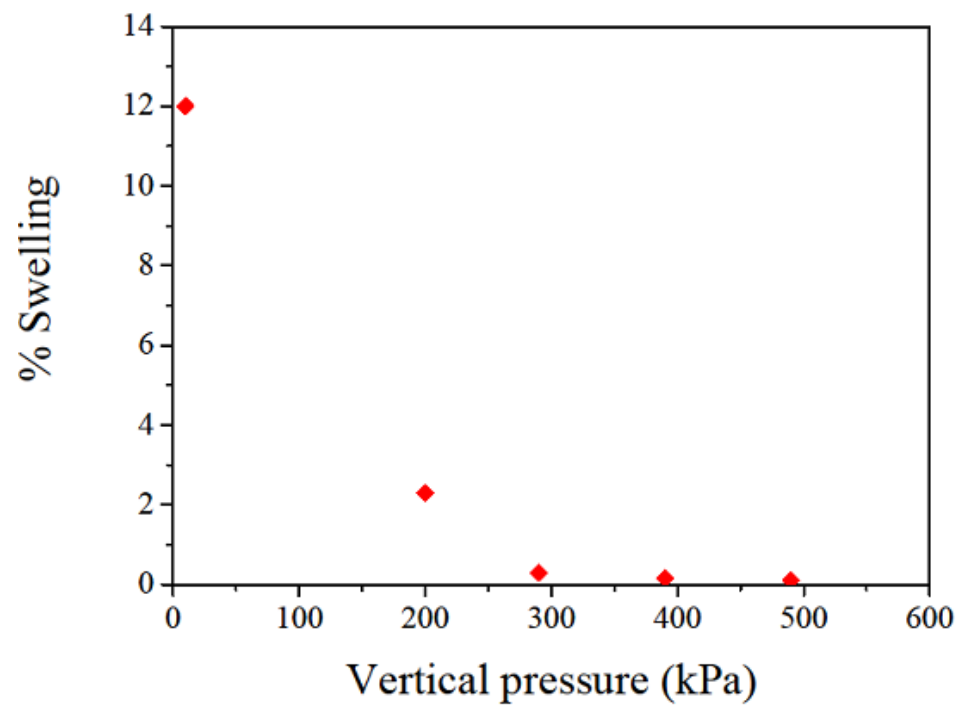

Fig. 3: Behavior of the Swelling Deformation of the Jurica's Natural Soil with the Vertical Initial Pressure.

In figure 4 the behavior of the aexp versus the vertical pressure is presented. The graphic decreases exponentially with the vertical pressure increment. The threshold of $300 \mathrm{kPa}$ is present herein again, when the aexp is very close to zero.

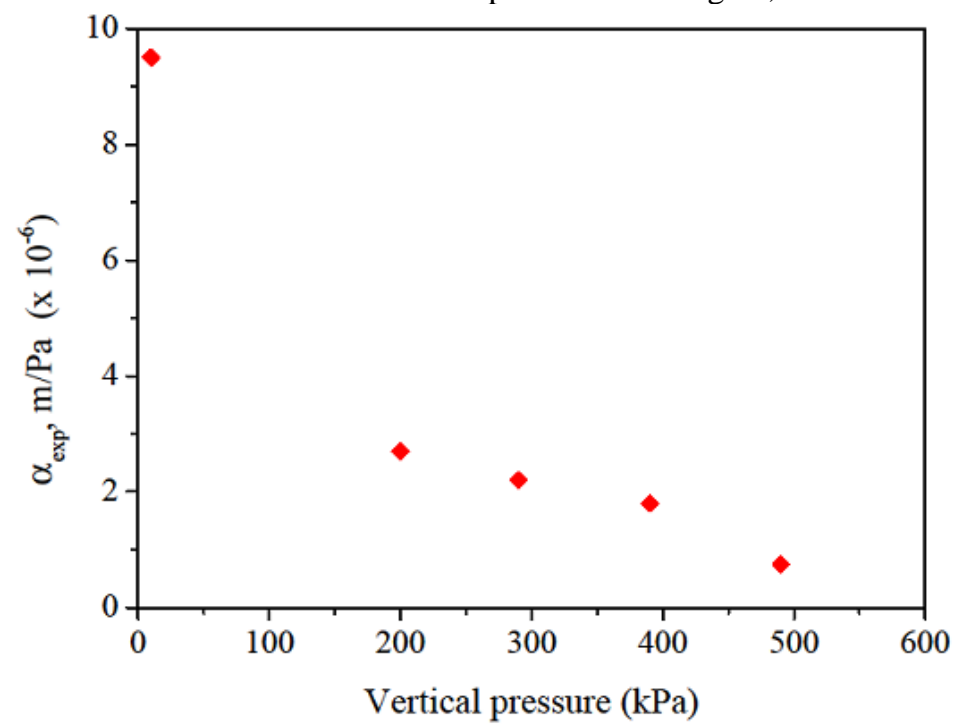

Fig. 4: Relationship between the Coefficient and the Vertical External Pressure for Jurica's Soil.

\section{Conclusions}

A methodology is presented for the calculation of the settlements of buildings constructed on expansive soils. The traditional methods for these problemes use parameters obtained from oedometric tests realized with saturated soils. Although it is the surest way to analyze the problem, the final settlements in expansive soils are overestimated.

The coefficient of volumetric deformation determined here can be part of a methodology that includes soil-structure interaction algorithms, which take into account the behavior from the expansive soil for the prediction of final settlements in a building on which the soil expansion pressure acts. In the determination of the coefficient aexp is necessary to know the initial conditions of the soil in the same way as the foundation structure that is going away to construct on since this one is function as much of the soil insitu property like of the external load.

Also, is interesting to observe from graphics in figures 4 and 5 that it can be concluded that for each kind of soil, it could exist a threshold of external pressure since it can be hoped settlements in an expansive soil.

This methodology must be carefully applied since the expansion pressure is developed only if the soil is hydrated, which doubtlessly will be reflected in a decrease of the bearing capacity of the ground. The diminution of the bearing capacity of the expansive soil when hydrating itself under a static pressure was not studied for this work and will be object of a next investigation. 


\section{Acknowledgements}

The authors wish to thank the Laboratory of Soil Mechanics and Materials at the Autonomous University of Queretaro for the use of equipment as well as the National Science and Technology Council of the Mexican Government (CONACyT) for the financial support through scholarships for postgraduate studies.

\section{References}

[1] J. A. Zepeda G., H. Casta-eda. Estado del arte de las cimentaciones sobre arcillas expansivas. Trabajo de Investigación; Facultad de Ingeniería, Universidad Autónoma de Querétaro, Querétaro, Querétaro, México. (1987)

[2] J. P. Krohn, and J. E. Slosson. Assessment of Expansive Soils in the United States. Proc. 4th International Conference on Expansive Soils, Denver, CO, 1, (1980) 596-608.

[3] Geology.com. "Expansive soil", Basement \& Foundation problems, http://geology.com/articles/expansive-soils.html. Accessed in June 2011.

[4] M. Yenes, J. Nespereira, J. A. Blanco, M. Suárez, S. Monterrubio, and C. Iglesias. Shallow foundations on expansive soils: a case study of the El Viso Geotechnical Unit, Salamanca, Spain. Earth and Environmental Science, Bulletin of Engineering Geology and the Environment, (2012). (71): 51-59. http://dx.doi.org/10.1007/s10064-010-0337-4.

[5] R. Rajapakse, CCM, CCE, PE. Pile Design in Expansive Soils. Pile Design and Construction Rules of Thumb, Butterworth-Henemann (Elsevier), Oxford UK; (2008) pages 279-281. http://dx.doi.org/10.1016/B978-0-7506-8763-8.00015-5.

[6] E. Kausel. Early history of soil-structure interaction, Soil Dyn Earthquake Eng doi:10.1016/j.soildyn.2009.11.001, U.S.A. (2009) http://dx.doi.org/10.1016/j.soildyn.2009.11.001.

[7] C. Lucian. Geotechnical Aspects of Buildings on Expansive Soils in Kibaha Tanzania, Doctoral Thesis, Division of Soil and Rock Mechanics, Department of Civil and Architectural Engineering, Royal Institute of Technology. Stockholm, Sweden. (2008).

[8] A. Sridharan and D. Choudhury. Swelling pressure of sodium montmorillonites. Geotechnique (2002) 52:459-462. http://dx.doi.org/10.1680/geot.2002.52.6.459.

[9] J. A. Zepeda, M. L. Perez-Rea and J. Cortés. Expansive soil properties in the Queretaro Valley. Proceedings of the 7th International Conference on Expansive Soil, Dallas, Tx. U.S.A. (1992).

[10] J. D. Nelson, D. J. Miller. Expansive Soils, Problems and Practice in Foundation and Pavement Engineering; Edit. John Wiley \& Sans, Inc. (1992).

[11] H. C. Lee and W. K. Wray. Techniques to Evaluate Soil Suction--A Vital Unsaturated Soil Water Variable. Proceedings of 1st International Conference on Unsaturated Soils, Paris, September (1995), Vol. II, pp. 615-622.

[12] W. G. Holtz. Expansive clays properties and problems. Quart. Colorado School Mines (1959) 54(4).

[13] L. Zeevaert, L. Interacción Suelo-Estructura de Cimentación, Edit. Limusa, D.F. México. (1980).

[14] M. L. Pérez-Rea, O. Cabrera. Predicción de la deformación volumétrica por hidratación en UN suelo expansivo, XXI Reunión Nacional de Mecánica de Suelos, Sociedad Mexicana de Mecánica de Suelos, México. (2002) Vol. 1, pp. 159-166. 